\title{
ANALYSIS OF PRACTICES OF CITIZEN ENGAGEMENT IN URBAN PLANNING (ON MATERIALS OF INTERNATIONAL PUBLIC PARTICIPATION FORUM «EMPOWERING CITIZENS, RESHAPING CITIES: PUBLIC PARTICIPATION AND URBAN DEVELOPMENT», 18-19 APRIL 2019, SAINT-PETERSBURG) \\ Abstract
}

The article is a review of International Public Participation Forum «Empowering Citizens, Reshaping Cities: Public Participation and Urban Development», which was held on April, 18-19, 2019 in Saint-Petersburg. The guests from Russua, Spain, Portugal, Brazil, Italy, Iceland, Moldova, Armenia, Kazakhstan, Turkey, South Korea and China shared their experience and reported the examples of how participatory democracy practices are implemented worldwide. Various online and offline approaches to citizen engagement are analysed.

Keywords: participatory management, participatory budgeting, initiative budgeting, citizen engagement, public participation, direct democracy, public participation, committee of citizens, territorial development.

\section{References}

1. Dias N. (org.) Hope for Democracy. 30 Years of Participatory Budgeting Worldwide. Epopeia Records | Oficina, 2018.

2. Vahtina M.A., Ignatova T.V., Polyanin A.V. Institucional'nyj status obshchestvennogo obsuzh-deniya zakonoproektov $\mathrm{v}$ sisteme publichnogo upravleniya // Izvestiya YUgo-Zapadnogo gosudar-stvennogo universiteta. Seriya: Ekonomika. Sociologiya. Menedzhment. 2018. № 6. P. 237-245.

3. "Trust in government, policy effectiveness and the governance agenda", in Government at a Glance, OECD Publishing, Paris, 2013.

4. Peixoto T., Fox J. When Does ICT-Enabled Citizen Voice Lead to Government Responsiveness? Digital Dividends Background Paper, World Development Report, 2016.

5. Peixoto T., Sjoberg F.M., Mellon J., Spada P. Effects of the Internet on Participation: Study of a Public Policy Referendum in Brazil. Policy Research Working Paper 7204, Governance Global Practice Group, World Bank, 2015.

6. Kyurdzhiev S.P., Kityukova D.S. Prozrachnost' i podotchetnost' kak ob"ektivnoe uslovie povy-sheniya effektivnosti mestnogo samoupravleniya // Nauka i obrazovanie: hozyajstvo i ekono-mika; predprinimatel'stvo; pravo i upravlenie. 2015. № 4 (59). P. 88 - 91.

7. Vagin V.V. K voprosu o teorii razvitiya i regulirovaniya iniciativnogo byudzhetirovaniya v sub"ektah Rossijskoj Federacii // Municipal'naya vlast'. 2016. № 1.

8. Ponomareva A.M., Ignatova T.V. Razrabotka matricy innovacionno-kreativnogo razvitiya go-roda na osnove indeksnogo metoda // Journal of economic regulation (Voprosy regulirovaniya ekonomiki). 2018. T. 9. № 3. P. 37 - 47.

\section{ЭФФЕКТИВНЫЕ ДЕЛОВЫЕ КОММУНИКАЦИИ В СИСТЕМЕ ГОСУДАРСТВЕННОГО УПРАВЛЕНИЯ}
Ериова
Наталья
Анатольевна
кандидат экономических наук, доцент кафедры госуправления
во внешнеполитической деятельности, Дипломатическая академия МИД России (119021, Россия, г. Москва, ул. Остоженка, 53/2, стр. 1).
E-mail: nataly_ershova@mail.ru
Моисеев
Анатолий
Васильевич
кандидат военных наук, профессор кафедры госуправления во внешнеполитической деятельности, Дипломатическая академия МИД России (119021, Россия, г. Москва, ул. Остоженка, 53/2, стр. 1). E-mail: moiseevanvas@mail.ru

\section{Аннотация}

Статья посвящена актуальной проблеме анализа деловых коммуникаций на разных уровнях государственного управления как способ повышения качества и доступности государственных услуг в РФ в условиях рынка. Деловая коммуникация является основой жизнедеятельности любой структуры, подразделения, органов, представляющих государственную власть. Необходима для исполнения управленческих решений, обратной связи, корректировки цели и этапов деятельности системы государственного управления. Рассмотрены проблемы коммуникаций в организациях государственной сферы. Сформулированы конкретные предложения по совершенствованию осуществления деловых коммуникаций в сфере государственного управления, в целях повышения эффективности работы государственных гражданских и муниципальных служащих.

Ключевые слова: деловая коммуникация, система государственного управления, повышение эффективности работы государственных гражданских и муниципальных служащих, управленческие решения, традиционные и инновационные технологии передачи информации, деловое общение, информационный обмен, профессиональная деятельность, взаимообмен информацией.

Актуальность вопроса, который затрагивается в данной статье, обусловлена тем, что деловая коммуникация занимает ведущие позиции в системе управления, поскольку является основой жизнедеятельности любой структуры, организации, подразделения, учреждения Особенно это важно для органов, представляющих местное самоуправление и государственную власть. Невозможно без 
делового общения представлять и исполнять управленческие решения, а также осуществлять обратную связь, корректировать цели и этапы деятельности органов власти. Как руководители, так и подчиненные должны владеть и эффективно пользоваться основными принципами деловых коммуникаций, а также традиционными и инновационными технологиями передачи информации.

Поэтому, необходимо формирование и развитие профессиональных компетенций специалистов в сфере современных знаний, а также аналитических навыков по современным проблемам, своей профессиональной деятельности и совершенствования навыков делового общения в целях повышения эффективности работы государственных гражданских и муниципальных служащих.

Научная литература дает множество определений коммуникации, что объясняется многоаспектностью и многогранностью данного явления. В широком смысле слова коммуникация (лат. communication - сообщение, передача) - это информационный обмен, который осуществляется вербально или же с использованием знаковых систем разных видов [1].

Ричард Л. Дафт дал следующее определение коммуникации, наиболее полно раскрывающее ее суть: коммуникация - это процесс, во время которого происходит взаимообмен информацией и ее осознание между двумя или более собеседниками [2] (рис. 1).

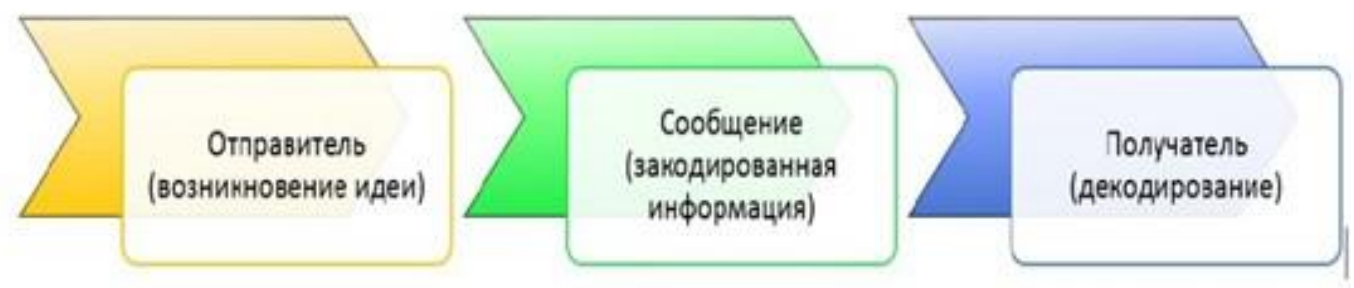

Рис. 1. Процесс коммуникаций

Также можно отметить, что коммуникация - это специфическая функция управления, представляющая собой умение особого рода и требующая определенных управленческих знаний и навыков. можно выделить следующие функции, которые реализует коммуникация: управленческая, информативная, эмотивная (связанная с экспрессивной стороной общения, эмоциями), фатическая (связанная с установлением контактов), контрольная (табл. 1) [3, с. 118].

Таблица 1

Функции коммуникации

\begin{tabular}{|l|l|}
\hline \multicolumn{1}{|c|}{ Функция коммуникации } & \multicolumn{1}{c|}{ Содержание функции } \\
\hline Управленческая & Побуждение адресата к действиям \\
\hline Информативная & Обмен сообщениями, мнениями, смыслами, решениями \\
\hline Эмотивная & $\begin{array}{l}\text { Выражение субъектом своего эмоционального отношения к теме } \\
\text { или ситуации }\end{array}$ \\
\hline Фатическая & $\begin{array}{l}\text { Возникновение, поддержание и окончание общения, фокусировка на } \\
\text { контактном элементе ситуации }\end{array}$ \\
\hline Контрольная & $\begin{array}{l}\text { Отслеживание поведения сотрудников различными способами на } \\
\text { основе иерархии и формальной соподчиненности }\end{array}$ \\
\hline
\end{tabular}

Целью деловой коммуникации является разработка и оптимизация определенного вида деятельности: административной, производственной, финансовой и т.д.

Если деловые коммуникации рассматривать в качестве одной из функций управления, то следует говорить об обмене информационными потоками, познаниями в определенных областях, интеллектуальными правами при взаимодействии индивидуумов, социальных групп, сообществ, экономических систем. Практически все, что делается руководителями для достижения определенных целей, основано на эффективном информационном обмене.

В области администрирования любой организации деловые коммуникации являются одним из вопросов, неизменно вызывающим дискуссии Эффективное взаимодействие всех структурных подразделений необходимо обеспечить для достижения целей, поставленных перед организацией, Однако, одной из наиболее серьезных, недостаточно проработанных проблем, в системе государственного управления является именно организация коммуникационного процесса. Необходимо также отметить, что на сегодняшний день значительно изменилось отношение науки к вопросам коммуникации.

В последние несколько лет во всем мире особое внимание уделяется вопросам эффективного взаимодействия и информационно-коммуникационным технологиям, разрабатываются и реализу- 
ются комплексные программы по их развитию. Эффективная коммуникация особенно важна для деятельности органов государственного управления, включая образовательную сферу.

В связи с развитием «цифровой экономики» и информационного общества социальное взаимодействие в системе госуправления все больше получает электронную форму выражения. Благодаря новейшим тенденциям усовершенствования на линии власть-информация-общественность меняется сама основа коммуникативной деятельности элементов государственной власти. Упрощается, приобретает большую эффективность обмен информацией, который происходит между государством и общественностью. Особое отношение к информации, которая вращается в системе социальных взаимодействий в структурах власти, предполагает выстраивание управленческой системы. На эффективность процесса принятия решений в сфере управления значительное влияние оказывает качество и эмоциональный оттенок передаваемой информации. В современных условиях именно качество и критерии для отбора информации играют решающую роль, поскольку информация должна быть максимально прагматичной. Диалог между властью и общественностью посредством Интернета в значительной мере совершенствует потоки информации, проходящие по системе государственного администрирования

Необходимо учитывать некое отличие индустриальной эпохи - социальное взаимодействие в ней было представлено двумя типами - письменным и устным, тогда как в информационном обществе доминирующее положение занимает третий тип - опосредованное электронное социальное взаимодействие. Что в системе государственного администрирования приводит к демассификации социальных коммуникаций. [4].

Общественность получает значительную свободу выбора информации. В индивидуальном режиме реципиент может самостоятельно выбирать именно ту информацию, в которой нуждается именно он. Так социально-коммуникативный процесс электронное социальное взаимодействие смещается из плоскости власти в плоскость общественности [5]. Электронный вид социального взаимодействия широко представлен в виде электронного администрирования, которое на данный момент является главнейшим новшеством в системе совершенствования общественных связей между гражданами и госорганами. Качество предоставления административных услуг в развитых странах значительно возросло именно благодаря деятельности электронной власти. Постоянный обмен информацией, который происходит между гражданами и властью, дает возможность более быстро и демократично удовлетворять актуальные потребности

Существует три вида коммуникации госорганов с гражданами, которые предусмотрены стратегиями электронных правительств

- правительство и граждане

- правительство и бизнес

- правительство-правительство

Принцип «обратной связи»- важнейший способ модернизации взаимодействия в системе госуправления, предполагает восприятие сообщений (инициатив или реакций) от членов общества, к которым обращены поддерживаемые коммуникации. В числе технологичных способов «обратной связи» сейчас практикуются:

- «прямые (горячие) линии» общения по телефонной связи;

- связи аналогичные «линии» в теле- и радиопередачах и в Интернете (на форумах интернетпорталов, в социальных сетях (Вконтакте, Фэйсбук и т.п.) ;

- заседания (конференции) по обмену мнениями в режиме круглых столов

- социологические опросы на разные темы и ряд других, идущих на смену прежде популярному методу почтовой доставки писем граждан и других произведений эпистолярного жанра

Обмен информацией, который происходит между государством и общественностью, упрощается, приобретает большую эффективность благодаря новейшим тенденциям усовершенствования коммуникаций.

Важное значение имеет развитие цифровых технологий в государственном секторе экономики. Развитие «цифровой экономики» обеспечивает возможность коммуникаций, обмена идеями и опытом. Площадки в интернете позволяют объединять усилия для создания бизнеса, инвестирования, поиска сотрудников, партнеров, ресурсов и рынков сбыта. Цифровые технологии также могут играть ключевую роль в обучении сотрудников, обмене знаниями, реализации инновационных идей, в том числе и в социальной сфере [6].

Все чаще «Цифровое правительство» и сервисы по оказанию государственных услуг рассматриваются как средство уменьшения расходов, обеспечивающее при этом более эффективные услуги гражданам и бизнесу, а также являющееся частью усилий правительства по сохранению окружающей среды. «Цифровое правительство» и инновационные технологии могут обеспечить эффек- 
тивное участие государственного управления в формировании и реализации концепции «устойчивого развития». «Цифровое правительство» позволит государственным органам оказывать более качественные услуги и быть более открытыми для населения.

Анализ рисков, препятствующих созданию полноценной «цифровой экономики», заслуживает отдельного рассмотрения. Наряду со странами, активно внедряющими и использующими новые технологии, существуют целые регионы, отрезанные от глобальных информационных коммуникаций, не использующие преимущества, позволяющие перейти к новому типу функционирования экономической системы. Различия состоят не только в отсутствии или плохом функционировании институтов, но и в уровне технологий, низком уровне развития человеческого капитала или дефиците инвестиционных ресурсов. Рыночные отношения находятся в прямой зависимости от того насколько быстро и беспрепятственно распространяется информация.

Следует отметить среди разнообразных коммуникаций в сфере государственного управления - по месту возникновения есть как внешние, так и внутренние (рис. 2).

Деловые связи между разными структурными подразделениями, установившиеся на государственной службе, отражают горизонтальный и вертикальный тип связи, в также степень их участия в процессе выполнение общих заданий. Разработаны алгоритмы взаимодействия для организации функциональных связей, которые описывают детально роли каждого подразделения в реализации определенной функции. Для реализации этой цели, довольно часто, органами государственной власти используются методики обзоров, так называемых функциональных анализов. Регламенты закрепляют нормы деловой коммуникации, которые широко используются в деятельности государственной службы.

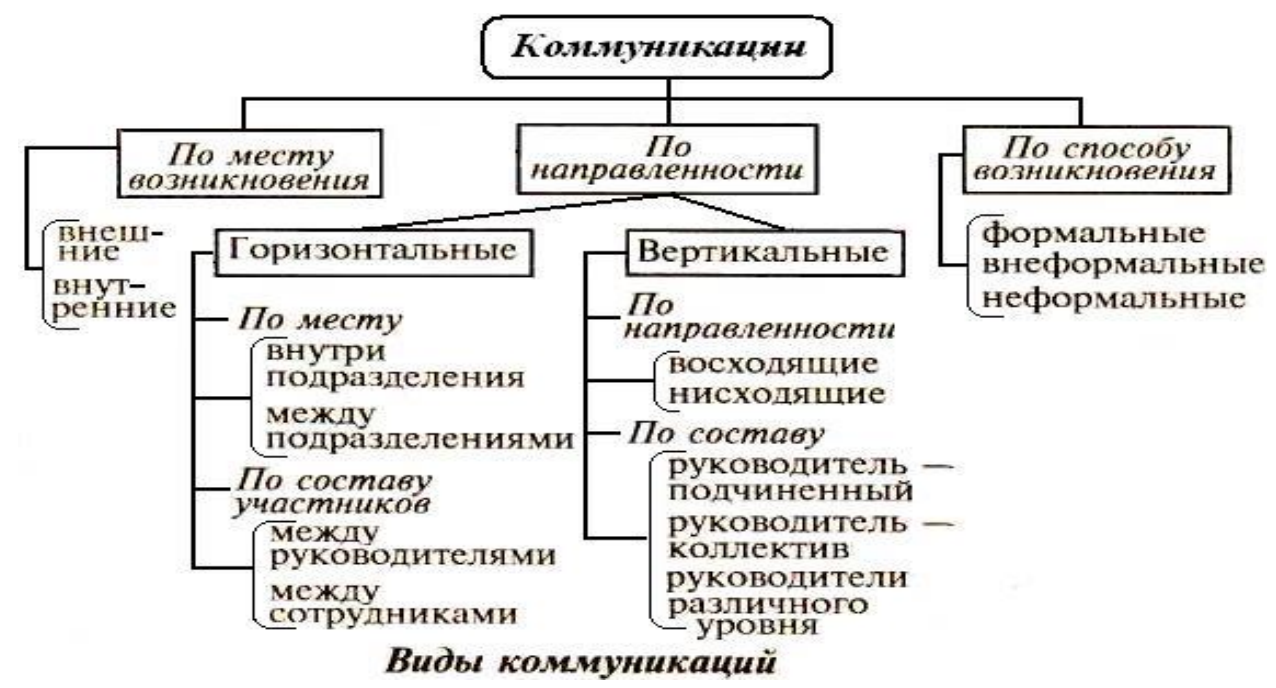

\section{Рис. 2. Классификация коммуникаций}

Трансформация устройства мировой экономики в «эпоху цифры» уже сильно повлияла на общественную жизнь в ряде стран. Дигитализация открывает перед людьми широкие возможности. Добиваться существенного роста экономических показателей, позволяют новые технологии, давая возможность переводить в онлайн все услуги и сервисы, повышать эффективность налоговой системы и бюджетных расходов. Но одновременно они и создают дополнительные угрозы. Поэтому необходимо прежде обеспечить юридическую значимость этих действий. Нужны законодательные изменения. В том числе и для того, чтобы снизить риски тех глобальных технологических перемен, которые уже наступают в России.

«Технологическая трансформация может не только привести к взрывному росту производительности труда, но и убить целые профессии, усилить риски поляризации доходов людей, - отметил в ходе пленарной сессии Председатель Правительства РФ Д.А. Медведев. - И для нас критически важна готовность к новым вызовам таких ключевых государственных институтов, как системы образования, здравоохранения, социальной помощи, поддержки занятости, а также модернизация государственного аппарата, с тем чтобы все типовые, рутинные операции были переведены в цифровой вид» ${ }^{1}$.

Важное значение имеет развитие цифровых технологий в государственном секторе.

Для совершенствования качества государственного управления необходимо:

\footnotetext{
${ }^{1}$ Московский финансовый форум (https://news.softodrom.ru/ap/b29159.shtml) (дата обращения 16.06.2019)
} 
- внедрять новые технологии в работе министерств и ведомств, причем эти технологии должны не просто соответствовать, а опережать развитие гражданского общества;

- повышать открытость и уровень доверия между гражданами и государством;

- сокращать избыточные контрольно-надзорные функции, которые являются одним из следствий недостатка такого доверия;

- адаптировать и разумно внедрять заимствованный опыт других стран

Классифицировать методы, формы и каналы государственной коммуникации можно по разным основаниям. Известный исследователь политико-коммуникативных процессов Р.-Ж. Шварценберг выделяет следующие каналы:

1) коммуникация через неформальные каналы;

2) коммуникация через организации;

3) коммуникация через средства массовой информации [7, с. 174].

Процесс государственной коммуникации состоит из элементов, являющихся типичными для любого коммуникативного акта: коммуникатор (органы государственного управления различных ветвей и уровней власти); само сообщение (официальная и неофициальная информация, устная или письменная, вербальная и невербальная); получатель (общество в целом, различные институты гражданского общества, индивидуальный реципиент); каналы распространения информации (межличностные, институциональные и массовые); каналы обратной связи (просьбы, обращения граждан, различные формы политического участия и т.п.); процесс кодирования-декодирования информации (подготовка информационных сообщений, их адекватная интерпретация аудиторией и т.п.); различного рода помехи (технические, семантические, психологические). В данном процессе можно выделить различные виды (в зависимости от ветви власти: законодательная, судебная, исполнительная), уровни (федеральная, региональная, местная), направленности (вертикальная, горизонтальная), каждый из которых имеет не только особую специфику функционирования, но и набор используемых технологий и приемов взаимодействия [7].

Для плодотворной деятельности организации особенно важен вертикальный вид коммуникации руководитель - подчиненный.

Эффективное коммуникативное поведение руководителя (начальника) важно для успешной коммуникации, так как решение многих управленческих задач основано на взаимодействии людей - начальника с подчиненными, подчиненных друг с другом. Коммуникативное поведение руководителя (начальника) является одной из сторон процесса межличностной коммуникации, состоящей из этапов (рис. 3).

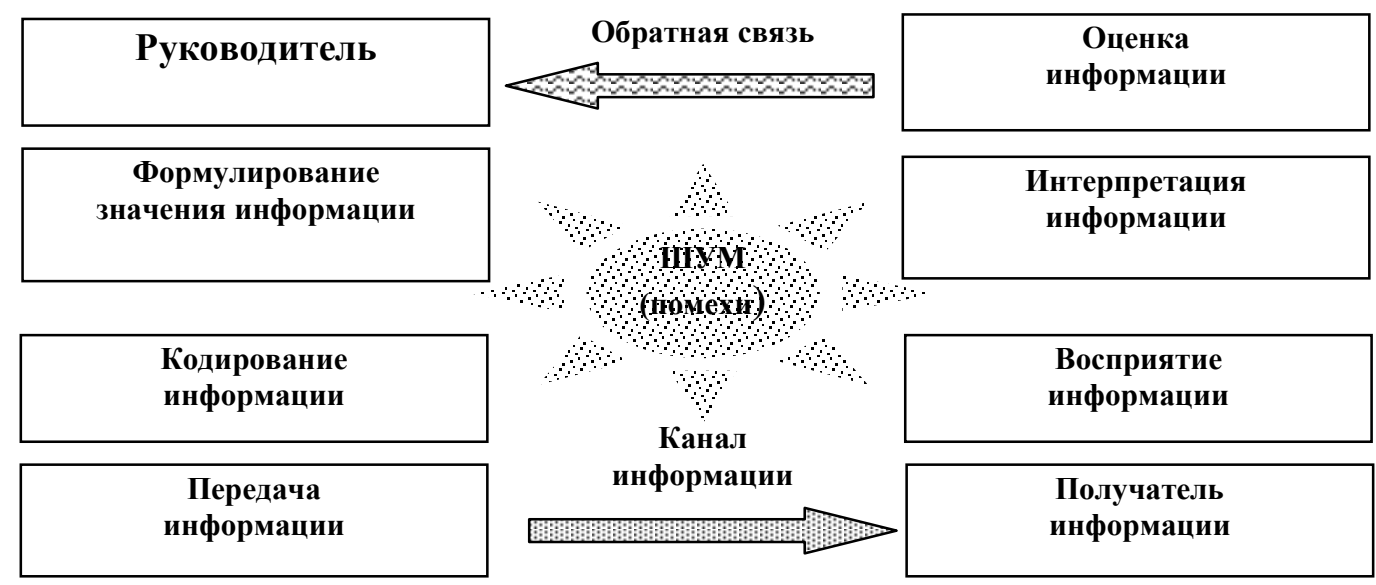

Рис. 3. Модель коммуникационного процесса

Начальным этапом общения руководителя с подчиненными являются проектирование сообщения, то есть формулирование смысла или значения информации, и ее кодирование. При этом под сообщением понимается информация (данные), помещенные в какую-либо форму и закодированные с помощью соответствующих (установленных) для определенной формы символов (знаков).

При проектировании сообщения происходит идентификация (кто я такой) руководителя в рамках коммуникативного процесса, формулирование значения того, что и почему он хочет передать подчиненному. Это во многом зависит от коммуникативных способностей руководителя. В качестве этих способностей выступают речь руководителя как средство общения, способность к межличностному восприятию и оценке индивидов, способность к социально-психологической адаптации к различным ситуациям, способность к контакту с другими людьми [8]. 
Сформированное послание содержит данные, которые наделены определенным значением, выражают принадлежащие руководителю мысли, идеи, указания, факты, ценности и взаимоотношения. Отправителем является лицо (должностное лицо, орган управления), стремящееся довести до получателя какую-либо информацию посредством ее передачи. При этом отправитель данного послания надеется, что значение данного послания будет восприниматься правильно. Чем больше разница между тем, что передается и что получено, тем ниже коммуникативные отношения руководителя.

Как пример можно привести трудности в коммуникации профессионалов определенных сфер деятельности с неподготовленной публикой, которые возникают в силу того, что первые облачают информацию в вид, который знают люди той же сферы деятельности (юридические и технические термины, специфическая аббревиатура, специальные символы и т.д.). Разница в переданной и полученной информации говорит об отсутствие у руководителя и получателя информации коммуникативных связей.

Передатчиком послания или информации может быть как сам руководитель (его голос, речь), так и другие средства (телефон, радио, ТВ, факс, компьютер и т.п.). После начала передачи сообщения или сигнала процесс связи выходит из-под контроля отправителя. На этом этапе завершается фаза отправления и начинается фаза получения передаваемой информации и понимания ее значения.

Для передачи информации задействуются каналы связи, то есть средства, с помощью которых осуществляется передача сообщения в пространстве и времени от отправителя к получателю.

Этап получения послания имеет не менее важную роль, чем все другие этапы этому предшествующие. Ключевая роль получателя состоит в том, чтобы фиксировать полученную информацию и в значительной степени раскодировать это сообщение в понятное и приемлемое для исполнителя значение. При раскодировании сообщения могут быть помехи или коммуникационные барьеры, которые ограничивают восприятие информации, возникающие либо в физическом окружении, либо в сфере человеческих эмоций человека, о чем говорилось выше.

Умение со стороны руководителя преодолевать эти барьеры может привести к повышению эффективности коммуникаций. Для этого надо: демонстрировать подчиненным интерес руководителя к информации от подчиненных; задействовать все возможные внутриорганизационные каналы коммуникации; повышать четкость, точность и однозначность сообщений; разделять с подчиненными ответственность за качество коммуникаций и обратной связи.

Важным элементом процесса коммуникации является обратная связь. Обратная связь-это ответ получателя на передачу сообщения. Она позволяет отправителю узнать, достигло ли сообщение получателя и в каком значении. Обратная связь для руководителя может выступать как в прямой форме (наблюдение непосредственного изменения поведения), так и в косвенной (снижение общей дисциплины, конфликты, низкая исполнительность и т.д.).

Информация, посланная без использования слов как системы кодирования, образует невербальное послание, лежащие в основе невербальной коммуникации. Для руководителя эта сфера межличностной коммуникации занимает очень важное место, поскольку в своей практике он зачастую значительную часть известных невербальных сигналов широко использует. К основным типам невербальной коммуникации относятся: движение тела, личные физические качества, речь, использование среды, физическая среда, время.

В процессе управленческой деятельности для организации информационного обмена и общения с подчиненными каждый руководитель формирует коммуникационные отношения, которые выстраиваются в виде определенный схемы или сети.

Коммуникационная сеть - связанные определенным образом люди, вовлеченные в информационный процесс с помощью информационных потоков. Она включает в себя комбинационные отношения между отдельными лицами, потоки сообщений между двумя или более лицами.

Создаваемая руководителем сеть состоит из вертикальных, горизонтальных и диагональных связей. В зависимости от того, как построены коммуникационные сети, деятельность организации может отличаться большей или меньшей эффективностью. В современных исследованиях установлено, что эффективность коммуникационного поведения по горизонтальным связям может достигать 90 \%, а по вертикальным, особенно если оно строится без учета обратных связей, составляет только $20-25 \%$.

Таким образом, эффективные деловые коммуникации во многом зависит от поведения руководителя в коммуникативном процессе. Ключевыми этапами процесса коммуникаций являются формулирование и доведение до исполнителей смысла выработанного решения или стоящей задачи, установление обратной связи с починенным для уяснения правильности понимания и готовности их к необходимым действиям. Наряду с традиционными способами коммуникативного общения для 
руководителя важное значение имеет умение использовать невербальные средства общения, что позволяет в существенной степени повысить эффективность управленческих коммуникаций [9].

Ведущим вопросом является в области деловых коммуникаций в системе государственного управления, то, каким образом можно преодолеть коммуникационные барьеры различного рода. На разных уровнях управления (федеральном, региональном и муниципальном) рассматриваются способы их преодоления, как способ повышения качества и доступности государственных услуг. Важна не только комплексная оптимизация государственных и муниципальных услуг, но и развитие системы электронной коммуникации граждан и юридических лиц с государством на всех стадиях предоставления услуг.

Зачастую мы сталкиваемся с различного рода информационно-коммуникационными барьерами, которые возникают, несмотря на наше умение пользоваться средствами коммуникации для решения тех или иных личных и профессиональных задач. Наибольший интерес представляют субъективные коммуникационные барьеры, влияние которых и будет рассмотрено ниже.

К субъективным барьерам общения относятся три основных вида:

- социально-культурные;

- психологические;

- барьеры понимания.

Все типы барьеров имеют взаимосвязь друг с другом, граница между ними в любой классификации весьма условна, и все они взаимосвязаны. В качестве причин возникновения субъективных барьеров общения могут рассматриваться непонимание, неприязнь, агрессия, неуверенность, некомпетентность, незаинтересованность, несовпадение уровней и способов восприятия участников коммуникации [10].

Для успешности коммуникации важно не столько то, насколько чётко и точно сформулирована передаваемая мысль, сколько то, совпадают ли взаимодействующие стороны в ее интерпретациях или нет (рис. 4).

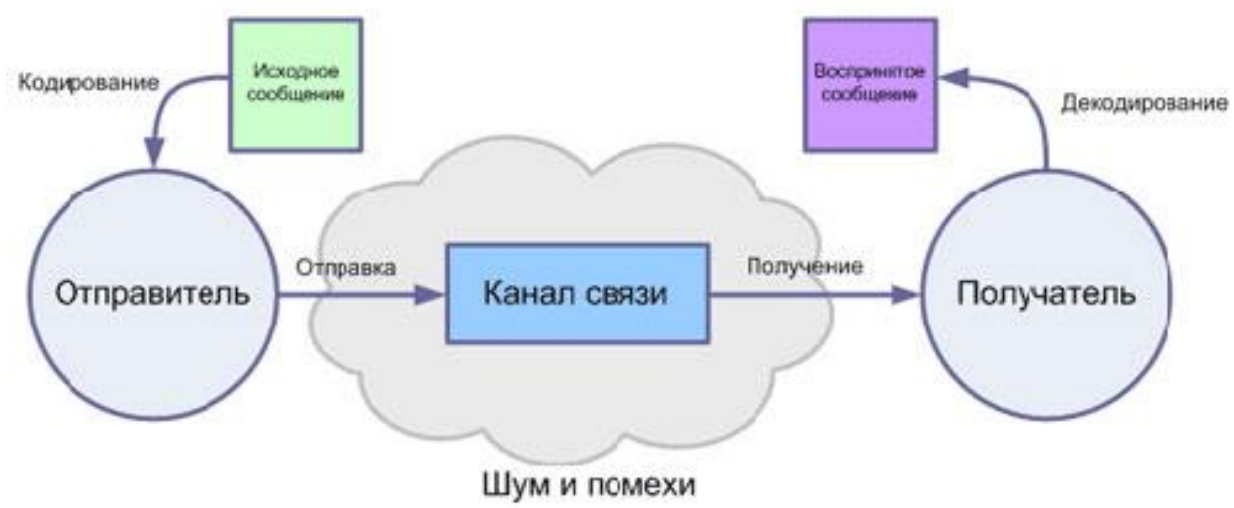

Рис. 4. Модель межличностной коммуникации

Результаты исследований по определению барьеров понимания подтверждают предыдущие результаты. Ключевым проблемным моментом для коммуникации являются барьеры эмоционального характера.

По данным московского представительства английской аудиторской компании KPMG проблемной областью для многих российских сотрудников также является EQ (позитивная эмоциональная составляющая) [10].

Выводы: Проблемы деловых коммуникаций на разных уровнях государственного управления

- бюрократизм и коррупция как характерные черты рыночной экономики, этические проблемы: общие черты и национальные особенности;

- нарушения моральных и правовых норм, вследствие, как условия - отсутствия эффективных средств контроля и закрытого характера госаппарата;

- групповой эгоизм (корпоративизм);

- присвоения властных функций в ущерб исполнительным, опасность подмены моральных требований общества корпоративными интересами госаппарата;

- понятие моральной структуры личности: нравственные чувства, моральные взгляды и убеждения;

- трудности подбора управленческих кадров на основе учета нравственных характеристик;

- проблема нравственного совершенствования управленческих кадров. 
В условиях глобализации экономики необходимы новые методы управления, использующие новые подходы в стратегии развития предприятий, совершенствование стиля и управленческих процедур, что возможно только в условиях формирования и внедрения управленческих инноваций.

\section{Рекомендации по увеличению эфбективности деловых коммуникаций в системе государственного управления}

- координация исходящей информации;

- выбор и анализ, тщательная подготовка, не только стратегически важных направлений информационной деятельности, но и конкретных заданий каждой PR-акции или кампании;

- установление прямых и обратных связей с гражданами, представителями бизнеса, общественными объединениями и организациями, СМИ;

- способы формирования желаемых нравственных качеств: этическое обучение, тренинги, этические деловые игры, создание комиссий по профессиональной этике, учет этических характеристик при аттестации сотрудников;

- нравственное самосовершенствование;

- передача информации относительно деятельности органа государственной власти;

- работа с обращениями, поданными гражданами и организациями;

- предоставление и получение сведений во время оказания услуг;

Деловые связи между органами государственными власти и организациями, предприятиями и гражданами выражаются в таких формах, как подписание соглашений и договоров.

При этом работе с бизнес-структурами, общественными объединениями и организаций некоммерческого типа в направлениях, связанных с социально-экономическим развитием, сейчас оказывается особое внимание. Подобная форма деловых контактов помогает развивать систему социального партнерства, которое подразумевает взаимодействие органов государственной власти с институтами гражданского общества. Социальное партнерство может рассматриваться в качестве действенного метода решения социально-экономических проблем и способа слияния гражданских интересов с государственными.

С точки зрения этики, социальное партнерство является общением, основанным на взаимном уважении между разными общественными элементами, представленными государственными структурами и ассоциациями граждан.

\section{Литература}

1. Богомолова М.Н. Роль коммуникации в современном гражданском обществе // Гуманитарные научные исследования. 2012. № 9 [Электронный ресурс]. URL http://human.snauka.ru/2012/09/1654

2. Волкова B.C. Внутриорганизационные коммуникации. Анализ системы внутриорганизационных коммуникаций // Экономика и менеджмент инновационных технологий. 2014. № 3 [Электронный реcypc]. URL: http://ekonomika.snauka.ru/2014/03/3976 (дата обращения 10.06.2019)

3. Гапоненко А.Л., Савельева М.В. Теория управления : учебник и практикум. М.: Юрайт, 2013. 336 с.

4. Чумиков А.Н. Креативные технологии Паблик рилейшнз. М.: Инфра-М, 2012.

5. Воробьев Ю.Л. Коммуникативное взаимодействие гражданского общества и структур публичной власти как управленческий процесс. Автореферат диссертации по социологии, специальность ВАК РФ 22.00.08 http://cheloveknauka.com/kommunikativnoe-vzaimodeystvie-grazhdanskogo-obschestva-istruktur-publichnoy-vlasti-kak-upravlencheskiy-protsess\#ixzz5rcHh9s]x (дата обращения 10.06.2019)

6. Семячков К.А. Цифровая экономика и ее роль в управлении современными социально-экономическими отношениями // Современные технологии управления.

ISSN 2226-9339. - №8 (80). Номер статьи: 8001. Дата публикации: 2017-08-28. Режим доступа: https://sovman.ru/article/8001/(дата обращения 10.06.2019)

7. Шварценберг Р.Ж. Политическая социология. В 3-х ч. / Пер с фр. М., 1992. Ч. 1.

8. Управление карьерой офицера / Моисеев А.В., Смирнов Е.В., Пиунов В.В.: Монография / М.: BA РВСН им. Петра Великого, 2009. 288 с.

9. Управление персоналом /под общ. ред. проф. Моисеева А.В. Учебник / ISBN: 978-5-906690-31-9/ Балашиха: ВА РВСН им. Петра Великого, 2018. 416 с.

10. Ершова Н.A. Разработка управленческих решений в системе эффективного менеджмента: Монография. М.: МИРБИС, Перо, 2015. - 240 с. - На рус. яз. - ISBN 978-5-906847-33-1.

Ershova Natalya Anatolyevna, Candidate of Economic Sciences, Associate Professor, Department of Foreign Policy Public Administration, Diplomatic Academy of the Ministry of Foreign Affairs of Russian Federation (stroenie 1, Ostozhenka 53/2, Moscow, 119021, Russian Federation). E-mail: nataly_ershova@mai.ru

Moiseyev Anatoly Vasilyevich, PhD in Military sciences, Professor of the Department of Foreign Policy Public Administration, Diplomatic Academy of the Ministry of Foreign Affairs of Russian Federation (stroenie 1, Ostozhenka 53/2, Moscow, 119021, Russian Federation). E-mail: moiseevanvas@mail.ru 


\title{
Abstract
}

The article is devoted to the actual problem of business communications analysis at different levels of government as a way to improve the quality and availability of public services of the Russian Federation in the market. Business communication is the basis of the life of any structure, departments, bodies representing the state power. It is necessary to realize management decisions, to have feedback and to adjust goals and stages of the public administration system. The problems of communications in state organizations are considered. Particular proposals for improving the implementation of business communications in the field of public administration are formulated in order to improve the efficiency of public civil service and municipal employees work.

Keywords: business communication, system of public administration, increase in overall performance of the civil civil and local government officers, management decisions, traditional and innovative technologies of information transfer, business communication, information exchange, professional activity, interchange of information.

\section{References}

1. Bogomolova M.N. Rol' kommunikacii v sovremennom grazhdanskom obshchestve // Gumanitarnye nauchnye issledovaniya. 2012. № 9 [Elektronnyj resurs]. URL http://human.snauka.ru/2012/09/1654

2. Volkova V.S. Vnutriorganizacionnye kommunikacii. Analiz sistemy vnutriorganizacionnyh kommunikacij // Ekonomika i menedzhment innovacionnyh tekhnologij. 2014. № 3 [Elektronnyj resurs]. URL: http://ekonomika.snauka.ru/2014/03/3976 (data obrashcheniya 10.06.2019)

3. Gaponenko A.L., Savel'eva M.V. Teoriya upravleniya : uchebnik i praktikum. M.: YUrajt, 2013. 336 s.

4. CHumikov A.N. Kreativnye tekhnologii Pablik rilejshnz. M.: Infra-M, 2012.

5. Vorob'ev YU.L. Kommunikativnoe vzaimodejstvie grazhdanskogo obshchestva i struktur publichnoj vlasti kak upravlencheskij process. Avtoreferat dissertacii po sociologii, special'nost' VAK RF 22.00 .08 http://cheloveknauka.com/kommunikativnoe-vzaimodeystvie-grazhdanskogo-obschestva-i-struktur-publichnoyvlasti-kak-upravlencheskiy-protsess\#ixzz5rcHh9sJx (data obrashcheniya 10.06.2019)

6. Semyachkov K.A. Cifrovaya ekonomika i ee rol' v upravlenii sovremennymi social'no-ekonomicheskimi otnosheniyami // Sovremennye tekhnologii upravleniya. ISSN 2226-9339. - №8 (80). Nomer stat'i: 8001. Data publikacii: 2017-08-28. Rezhim dostupa: https://sovman.ru/article/8001/(data obrashcheniya 10.06.2019)

7. SHvarcenberg R.ZH. Politicheskaya sociologiya. V 3-h ch. / Per s fr. M., 1992. CH. 1.

8. Upravlenie kar'eroj oficera / Moiseev A.V., Smirnov E.V., Piunov V.V.: Monografiya / M.: VA RVSN im. Petra Velikogo, 2009. $288 \mathrm{~s}$

9. Upravlenie personalom /pod obshch. red. prof. Moiseeva A.V. Uchebnik / ISBN: 978-5-906690-31-9/ Balashiha: VA RVSN im. Petra Velikogo, 2018. 416 s.

10. Ershova N.A. Razrabotka upravlencheskih reshenij v sisteme effektivnogo menedzhmenta: Mo-nografiya. M.: MIRBIS, Pero, 2015. - 240 p. - Na rus. yaz. - ISBN 978-5-906847-33-1.

\section{КЛЮЧЕВЫЕ ПРОБЛЕМЫ РАЗВИТИЯ И УПРАВЛЕНИЯ В ДЕЯТЕЛЬНОСТИ ТРАНСНАЦИОНАЛЬНЫХ КОРПОРАЦИЙ В РОССИИ}

\author{
Жуков \\ Павел \\ кандидат экономических наук, доцент кафедры «Экономика и менеджмент», \\ Владимирович \\ Донской государственный технический университет (344006, Россия, \\ г. Ростов-на-Дону, пл. Гагарина, 1). E-mail: zhukovpv@bk.ru
}

\section{Аннотация}

В статье рассмотрены основные проблемы, с которыми сталкиваются отечественные ТНК. Отмечено, что существуют географические, экономические, организационно-правовые и финансовые проблемы, наличие которых не позволяет развивать деятельность ТНК на должном уровне и быть конкурентоспособными, по сравнению с остальными развитыми странами. Необходимо создать инфраструктуру, способствующую координации и организации деятельности ТНК в России, а также активно применять международный маркетинг и совершенствовать нормативно-правовое обеспечение деятельности не только ТНК, но и всего рынка в целом.

Ключевые слова: транснациональные корпорации, процесс глобализации, проблемы развития, инновационное развитие, бизнес-партнеры, инвестиции, инвестпроекты, транснационализация, отток капитала.

Экономические трудности, которые были связаны с переходом отечественной экономики от командной к рыночной, долгое время являлись препятствием вхождения России в процесс глобализации. В настоящее время по-прежнему остается риск того, что наша страна в условиях глобализации может оказаться на втором плане мирового прогресса, иначе говоря, запасным ресурсом. Именно поэтому важным является развитие транснационализации отечественных компаний, поскольку во многом от их развития зависит процесс глобализации в России. Тем не менее, несмотря 